\title{
“DE SELVAGEM A CIDADÃO”: REPRESENTAÇÕES SOCIAIS DO ÍNDIO NO ENSINO FUNDAMENTAL
}

"FROM WILD TO CITIZEN": SOCIAL REPRESENTATIONS OF THE INDIAN IN ELEMENTARY SCHOOL

Gerson Pereira Filho*

Alírio Ferreira Pinto

\begin{abstract}
RESUMO:
Historicamente vários processos articulados e constituídos na convivência e nas práticas sociais foram se formando em função de uma série de mecanismos heterogêneos, através de diferentes discursos, criando imagens e conceitos sobre o índio e sobre diferenças culturais. Um dos veículos de maior disseminação encontra-se na escola, sendo os docentes seus principais emissores. Na socialização de conhecimentos cotidianos e científicos as representações sociais do índio são formadas e transmitidas, muitas vezes, como axiomas sociais. Com a "Teoria das Representações Sociais" enquanto aporte teórico e metodológico utilizado na pesquisa, objetivou-se identificar, compreender e interpretar as representações sociais sobre o índio no Ensino Fundamental. Foram entrevistadas dezenove professoras em quatro escolas públicas em uma cidade do sul de Minas Gerais, sendo uma dessas escolas, indígena. Foram utilizados dois instrumentos de coleta de dados: a técnica de associação livre de palavras e um questionário. Os resultados apontaram forças sociais, históricas e culturais no balizamento dos vários critérios que prescreveram e convencionaram o ser índio e suas contradições, repercutindo ao mesmo tempo uma consciência histórica cultural, e outra de reivindicação e busca de reconhecimento e valorização diante de políticas públicas educacionais reverberantes à sua realidade e ao reconhecimento da diversidade étnica.
\end{abstract}

PALAVRAS-CHAVE: Índio. Representações sociais. Políticas educacionais. Diferenças culturais. Diversidade étnica.

\section{ABSTRACT:}

Historically, several processes have articulated and constituted in the relationship and in social practice have been forming on the basis of a series of mechanisms heterogeneous, through different discourses, creating images and concepts about the indian and about cultural differences. One of the vehicles of further dissemination are in school and the teachers their main emitters. In the socialization of knowledge, everyday science and the social representations of the indian are formed and transmitted, often, as axioms the social. With the "Theory of Social Representations" as a theoretical and methodological tools used in the research study, the objective was to identify, understand, and interpret the social representations of the indian in the Elementary School. Were interviews with nineteen teachers in four public schools in a city in the south of Minas Gerais, being one of these schools, indigenous. Were used two instruments collection: the technique of free association of words and a questionnaire. The results pointed out the social forces, historical and cultural at the boundary of the different criteria that prescribe and convencionalizaram the be indian, and their contradictions, reflecting

\footnotetext{
* Doutor em filosofia. Professor de Filosofia na PUC Minas (Poços de Caldas). E-mail: gerson@pucpcaldas.br.
} 
at the same time a consciousness of the historical, cultural, and other claim and the search for recognition and appreciation in the face of public educational policies reverberant to your reality and the recognition of ethnic diversity.

KEYWORDS: Indian. Social representations. Educational policies. Cultural diferences.

Ethnic diversity.

\section{INTRODUÇÃO}

Em 2008, a Lei no 9394/1996 correspondente às Diretrizes e Bases da Educação Nacional foi alterada, incorporando ao texto o artigo 26- A, a obrigatoriedade da inclusão do ensino das Culturas e História Afro-Brasileira e dos Povos Indígenas nos currículos de todas as escolas brasileiras (redação dada pela Lei $n^{\circ} 11.645 / 2008$ ). As políticas educacionais no Brasil voltadas para o tratamento da etnicidade foram se consolidando no contexto de busca da autoafirmação desses dois grupos pela vinculação de imagens mais condizentes com as suas realidades e identidades.

Reivindicações identitárias e multiculturais são, assim, causas do sentimento de perda das referências de grupos sociais sendo "frequentemente, sua única exigência a aplicação na realidade da prática social concreta (educação, trabalho, mobilidade social) a letra e o espírito igualitário da Constituição e suas leis" (SEMPRINI, 1999, p. 40). Com a implementação da referida lei surge o desafio de formação dos profissionais da educação em trabalhar questões étnico-raciais na desconstrução de estereótipos de raça, etnia, religião, como outras questões relacionadas à inferioriorização da diferença.

Como subsídio para orientar o trabalho em sala de aula, nos Parâmetros Curriculares Nacionais- PCNs estão contidos os objetivos gerais do Ensino Fundamental, que exigem ações específicas no tratamento da diversidade étnico-racial brasileira visando afetar todos os atores e dimensões do processo educativo, fundamentando a chamada temática da Pluralidade Cultural (BRASIL, 1997). Em linhas gerais corresponde ao conhecimento/reconhecimento e valorização das características étnicas e culturais dos diferentes grupos sociais que convivem no território nacional. A proposta é tornar a escola um espaço dinâmico de desconstrução monocultural do saber e do existir, descolonizando pensamentos e ações no sentido psicológico, filosófico, político e social.

O currículo escolar ocupa um lugar de luta cultural por construção de significados, com saberes produtores de representações da experiência da diferença conforme as referências socialmente admitidas sobre etnia, raça, gênero, classe, nos ocultamentos, nas falas, nas diferentes instâncias de produção discursiva onde a linguagem institui e demarca posições. Suas narrativas 
definem quais formas de conhecer são válidas ou não, o que é certo ou errado, o que é moral ou imoral, o que é bom ou mau, o que é belo e o que é feio, quais vozes são autorizadas e quais não são, representando sempre o olhar seletivo de alguém ou de um grupo na produção de conflitos e concessões culturais, políticas e econômicas que organizam e desorganizam um povo (SILVA, 1995, CORAZZZA, 2008, MACEDO, 2012). Admite-se também a existência de um "currículo oculto”, que comporta subliminarmente a transmissão de atitudes e valores pelas relações sociais, pelas rotinas do cotidiano escolar, pelos rituais e práticas, pelas regras e modos de organização (BRASIL, 2008, p.18).

$\mathrm{Na}$ atual configuração do ensino no Brasil, na Estrutura da Base Nacional Curricular Comum, está presente o "Tema Especial Culturas Indígenas e Africanas" relacionado ao reconhecimento do protagonismo de atores excluídos das narrativas históricas pelas desigualdades sociais e econômicas, marcantes na sociedade brasileira, promotoras da massificação cultural e consequentemente de desvalorização da diversidade e pluralidade cultural no país. O intuito é constituir um espaço pedagógico através da prática educativa, incorporando esse reconhecimento à formação das novas gerações (BRASIL. 2015).

A docência nesse sentido necessita ser compreendida e manifestada como ação educativa metódica e intencional, cindida em relações sociais, étnico-raciais e produtivas, influenciando conceitos, princípios e objetivos da Pedagogia (BRASIL, 2006a, p.1). Em face de realidades complexas, a postura educativa deve ser essencialmente "investigativa, integrativa e propositiva com vistas a contribuir para superação de exclusões sociais" sejam elas quais forem (BRASIL, 2006b, p. 2). Tal posicionamento enfatiza a possibilidade de desvelamento das posições adotadas e advindas de processos de formação, e pelo qual se estabelece o ideal de ruptura da reprodução dessas mesmas posições na formação dos alunos nas escolas da educação básica.

Entender a diversidade cultural na educação "implica desconstruir referências ideológicas, esclarecer referências teóricas, desvendar práticas sociais, ressignificar práticas pedagógicas, posicionar-se politicamente e situar-se socialmente" (JANOARIO, 2008, p. 55). Mais do que apenas promover a tolerância "é compreender e problematizar as representações sociais acerca das diferentes culturas" como por exemplo a cultura indígena. (SILVA; FONSECA, 2007, p. 46). 


\section{TEORIA DAS REPRESENTAÇÕES SOCIAIS}

As representações sociais são compreendidas como um conjunto de conceitos, proposições e explicações originadas na vida cotidiana no curso de comunicações interpessoais, nas teorias da vida cotidiana, nas narrativas e imaginários sociais que dão sustentabilidade à realidade socialmente construída (MOSCOVICI, 2015). Seu estudo e análise repousam sobre as trocas constituídas no processo relacional do psíquico com o social na construção da realidade. As instituições presentes em diferentes culturas possuem sistemas, normas e formas de organização que conduzem por uma parte à individualização, e de outra, à socialização. As representações carregam a marca dessa tensão constituindo sentidos e buscando mantê-las sob um limiar sustentável.

A “Teoria das Representações" inscreve uma proposta metodológica de integração entre o mundo individual e o mundo social, na compreensão de que os saberes individuais, para além de informações e ideologias imersos nas distintas estruturas sociais, determinam o modo de condução da experiência estampando singularidades, originalidades e excentricidades no mundo, influenciando na sociedade ao mesmo tempo em que seu contexto de vivência evidencia uma realidade social pela qual possibilitou o modo de pensar coletivo.

Em sua obra traduzida como “A Representação Social da Psicanálise” (1978), Moscovici buscou compreender como o conhecimento científico era consumido, transformado e utilizado pelas pessoas em seu cotidiano, mais precisamente investigando de que maneira alguns grupos da sociedade parisiense, como católicos e comunistas, referiam-se e atribuíam sentidos à teoria psicanalítica.

A estrutura de cada representação possui "duas faces tão pouco dissonantes quanto a página da frente e o verso de uma folha de papel: a face figurativa e a face simbólica." (MOSCOVICI 1978a, p. 65). A face figurativa se desdobra na aplicação de uma simbolização a um objeto que não está presente, enquanto a face simbólica corresponde ao modo de percepção do real conduzindo à recuperação do objeto, tornando presente e palpável, assim faz corresponder a toda figura um sentido e todo sentido uma figura. Representar um objeto "é ao mesmo tempo, conferir-lhe o status de um signo, é conhecê-lo, tornando-o significante" (MOSCOVICI, 1978b, p. 63). Como exemplo, o inconsciente enquanto signo da Psicanálise é visto por um lado carregado de valores, escondido, involuntário; e visualizado por outro lado, nas profundezas do cérebro, assim como a libido associada à concretude do ato sexual e à genitalidade, também cercada de conotações religiosas, políticas, posicionando os sujeitos através de fatores explicativos, característicos e hierárquicos. Nessa configuração estrutural de componentes simbólicos e figurativos, ocorre a duplicação de um sentido 
por uma figura, materializando um objeto abstrato, e a duplicação de uma figura por um sentido, propiciando contexto cognoscível ao objeto (MOSCOVICI,1978a, p. 65).

Presentes num referencial de pensamento preexistente inter-relacionado a um sistema de crenças, valores e imagens, dados a priori, as representações sociais são condicionadas pela linguagem e pela cultura exercendo uma "função prescritiva", de algo que existia anteriormente impondo sua força resultada, decretando o que deve ser pensado. (MOSCOVICI, 2015, p. 36). Através de sua "função convencionalista, dão uma forma definitiva, localizam em uma determinada categoria e gradualmente as põem como um modelo de determinado tipo, distinto e partilhado por um grupo de pessoas" (p. 34). Tudo o que é novo se junta ao modelo e se sintetiza nele. Como resultado, "a memória prevalece sobre a dedução, o passado sobre o presente, a resposta sobre o estímulo, as imagens sobre a realidade" (p. 55).

Sua finalidade medular é tornar algo desconhecido e inapropriado em algo familiar, interligado aos conhecimentos já internalizados e prescritos. Pela "ancoragem," ocorre sua estabilização e o seu manejo. O outro processo responsável por gerar as representações sociais denominado de "objetivação", traduz conceitos em imagens, abstração em uma substância quase tangível, sendo assimiladas com a sedimentação de um registro simbólico antes não constituído (MOSCOVICI, 1978).

Organizadas de maneiras distintas, segundo classes, culturas e grupos, as representações sociais estão presentes em sistemas de pensamento, constituindo tantos universos de opinião, quanto classes, culturas ou grupos. No "Universo Consensual” a sociedade é uma criação visível, contínua, permeada com sentido e finalidade, possuindo uma voz humana estabelecendo formas de pensar, explicar e elaborar a construção social do real, de acordo com as experiências pessoais. Assim, "as pessoas não são necessariamente cientistas despreparados, mas podem ser bons místicos ou filósofos da vida cotidiana." (MOSCOVICI, 2015, p. 332). Essa ordem no decorrer do tempo foi invertida, ou seja, "as ciências é que passaram a inventar e propor a maior parte dos objetos, conceitos, analogias, formas lógicas, a que a sociedade recorre quanto aos seus questionamentos econômicos, políticos e intelectuais" (MOSCOVICI, 1978, p. 20). Neste "Universo Reificado", as várias ciências interessadas em tais objetos podem, por assim dizer, impor sua autoridade no pensamento e na experiência de cada indivíduo e decidir, em cada caso particular, o que é verdadeiro e o que não o é. (MOSCOVICI, 2015, p. 50).

As representações sociais enquanto uma forma híbrida de conhecimento implicam compreender a apreensão e os impactos psicológicos desses universos, compreendendo os lugares que ocupam, de sua aproximação verificando como o conhecimento científico é apreendido, 
reelaborado e difundido socialmente As redes sociais educativas são estabelecidas e influenciadas por esses dois universos de pensamento, pelos processos pedagógicos, entremeadas ao conhecimento cotidiano sob interferências e influências individuais e coletivas dos recursos educativos utilizados pelo domínio ideológico nos interesses profissionais. Com esse aporte teórico objetivou- identificar, compreender e interpretar as representações sociais sobre o índio para 19 professoras do Ensino Fundamental de quatro escolas públicas em uma cidade do sul de Minas Gerais, sendo uma delas uma escola indígena.

\section{METODOLOGIA}

Considerando os objetivos e a proposta de investigação, este estudo foi elaborado a partir da técnica de pesquisa qualitativa. Enquanto pesquisa de campo dentro de um recorte espacial, levou-se em conta o estabelecimento do confronto da realidade com os pressupostos teóricos da pesquisa. O fenômeno ou o processo social deve ser entendido nas suas determinações e transformações dadas pelos sujeitos, numa relação intrínseca de oposição e complementaridade entre o mundo natural e social, entre o pensamento e a base material (MINAYO, 1998). A resistência à mudança e, ao mesmo tempo, a transformação que o senso comum e os conhecimentos científicos promovem, são aspectos paradoxais passíveis de observação e análise empírica.

\section{PARTICIPANTES}

Participaram da pesquisa 19 professoras atuantes em três escolas públicas municipais e em uma escola estadual indígena. A amostragem do presente estudo foi pautada nos critérios estabelecidos com base em pesquisas qualitativas, atrelada ao objeto de estudo e ao campo empírico de investigação. Os critérios corresponderam à escolha dos participantes da pesquisa mediante as características investigadas, valorizando a abrangência da diversidade do conjunto com a finalidade de identificar e reconhecer semelhanças e diferenças conforme as investigações realizadas e confrontadas com a teoria. 


\section{PROCEDIMENTO}

Inicialmente, foi feito um levantamento das escolas públicas existentes no município ${ }^{1}$ no qual foram encontradas um total de oito instituições, sendo escolhidas estrategicamente quatro escolas. Devido à extensa territorialidade do município optou-se por uma escolha mais distribuída objetivando um panorama de melhor abrangência do objeto de estudo. Posteriormente foi efetuado o contato com os professores do Ensino Fundamental (anos inicias) para assim esclarecer os objetivos da pesquisa e solicitar a autorização pessoal e institucional para a realização da pesquisa.

\section{INSTRUMENTO}

Foi organizado um conjunto de questões em forma de questionário com perguntas norteadoras básicas com a finalidade de traçar as características no âmbito individual e grupal, com perguntas fechadas averiguando características sócio-demográficas e características profissionais, e duas perguntas abertas (RICHARDSON, 1999, p. 190). Na tentativa de reduzir possíveis dificuldades contidas nas expressões discursivas do questionário, utilizou-se a técnica da associação livre de palavras.

Não restringindo a técnica somente ao motivo citado, compreende-se sua importância pela possibilidade da livre projeção mental dos participantes e de obtenção do conteúdo semântico a ser explorado (OLIVEIRA, MARQUES, GOMES, TEIXEIRA, 2005). Assim, baseado nos instrumentos, procurou-se compreender e analisar, revelando aspectos psicossociais, culturais, históricos, científicos na tentativa de aproximação da realidade docente em que poderiam ser formadas e identificadas as representações sociais.

\section{TRATAMENTO E ANÁLISE DOS DADOS}

Para o tratamento e análise da associação livre de palavras produzidas de acordo com suas frequências assim como as duas últimas perguntas do questionário optou-se pela Análise de Conteúdo "visando a obter, por procedimentos, sistemáticos e objetivos de descrição do

\footnotetext{
${ }^{1}$ Localizado no sul de Minas Gerais, o município de Caldas possui uma extensão territorial de 711,414 km², com uma população de 13.633 habitantes. Possui 3 distritos: São Pedro de Caldas, Santana de Caldas e Laranjeiras de Caldas e a Estância Hidromineral Pocinhos do Rio Verde, locais onde estão situadas três das escolas de referência da pesquisa. A Escola Estadual Indígena da comunidade Xucuru Kariri está localizada na área de abrangência da Fazenda Agropecuária Boa Vista fixada às margens da Rodovia BR 459 km 36, a 6 km da área urbana.
} 
conteúdo das mensagens, indicadores que permitam a inferência de conhecimentos relativos às suas condições de produção/recepção” (BARDIN, 1979a, p.48). As condições de produção/recepção relacionam-se às "variáveis psicológicas do indivíduo emissor, variáveis sociológicas e culturais, variáveis relativas à situação de comunicação ou do contexto de produção da mensagem" (BARDIN, 1979b, p. 48). O campo de determinação dos sentidos analisados corresponde aos conteúdos associados às manifestações linguísticas, psicológicas e sociais daquilo que foi coletado.

\section{RESULTADOS E DISCUSSÃO}

Das participantes da pesquisa, 5\% têm idade entre 21 a 25 anos, $21 \%$ entre 26 a 30 anos, $16 \%$ entre 31 a 35 anos, 26\% entre 36 a 40 anos, 16\% entre 41 a 45 anos, $10 \%$ entre 46 a 50 anos, e 5\% acima de 51 anos. São 100\% do sexo feminino, das quais 11\% possuem Ensino Médio Completo com Magistério, 26\% Ensino Superior e 63\% têm pós- graduação; 26\% lecionam há 1 a 5 anos, $5 \%$, de 5 a 10 anos e $69 \%$ há mais de 10 anos. Quanto à turma em que lecionam, $38 \%$ trabalham no $1^{\circ}$ Ano do Ensino Fundamental, 26\% com o $2^{\circ}$ Ano, e $21 \%$ no Ano $10 \%$ com o $4^{\circ}$ Ano e $5 \%$ no $3^{\circ}$ Ano do Ensino Fundamental. O tratamento dessas características é importante devido à proposta analítica de aspectos que poderiam ou não dizer sobre elementos de contribuição da formação das representações sociais sobre o índio no espaço escolar, tanto experiência docente, quanto pela formação e séries pelas quais são ministradas as atividades direcionadas ao tema.

\section{RELAÇÃO PRÁTICA COM A TEMÁTICA INDÍGENA}

Começando pela relação a respeito de processo de formação específica relacionada à temática, somente as docentes da escola indígena possuem. Com base no Referencial Curricular Nacional para as Escolas Indígenas seus principais princípios estão no reconhecimento e conservação da diversidade cultural e linguística, com o propósito de promover a comunicação e compartilhamento de experiências socioculturais, históricas e linguísticas distintas sem a sobreposição de valores inferiores ou superiores, além de estimular o entendimento e o respeito entre seres humanos de identidades étnicas diferentes, ainda que se reconheça que tais relações vêm ocorrendo historicamente em contextos de desigualdade social e política (BRASIL,1998). A análise desse resultado permeia, de certa forma, todas as outras questões como produção de materiais didáticos, metodologias, interesses, conhecimento sobre a legislação, entre outros. 
Sobre a lei 11.645/2008, $63 \%$ replicaram algum tipo de conhecimento, sendo $21 \%$ derivada da formação citada anteriormente, $16 \%$ de reuniões pedagógicas, $10 \%$ pela divulgação da Superintendência de Ensino, 10\% através da mídia e 6\% por meio da LBD. Assim $37 \%$ das entrevistadas desconhecem o instrumento legal de orientação e atribuição das instituições educacionais, considerando que 69\% lecionam há mais de 10 anos. Todas as professoras afirmaram realizar atividades relacionadas aos povos indígenas em sua maioria lúdicas. Dentre elas estão: rodas de conversa, pinturas, colagens, produção e leitura de textos, estudo da história e tradições, análise comparativa entre " índios atuais e antigos", caça-palavras, teatro, música e artesanato. No caso das docentes da escola indígena, também são realizadas reuniões com a liderança da comunidade, produções científicas próprias e de orientações seguidas por legislações específicas segundo o Referencial Curricular Nacional para as Escolas Indígenas. Dentre as entrevistadas, uma referiu-se a visita realizada à comunidade indígena localizada no município.

A maioria das participantes da pesquisa respondeu se interessar pelo tema. Cerca de $63 \%$ justificaram sua resposta pela valorização da cultura e da contribuição dos povos indígenas na história do Brasil e de seus direitos, $10 \%$ por curiosidade pessoal e $5 \%$ pela diferença do índio em relação ao homem branco. Uma das entrevistadas atribuiu seu desinteresse pela falta de estímulo e motivação quando criança e por não lecionar para alunos indígenas. As professoras da escola indígena denotaram conhecimento sobre outras comunidades, como por exemplo, os Pataxós, os Krenak, os Xacriabá, os Maxacali e os Caxixos. Cabe considerar, nesse resultado, o fato de $21 \%$ das participantes residirem e lecionarem na comunidade citada, o que reduziria o percentual de conhecimento sobre comunidades indígenas em $52 \%$.

Os resultados mantiveram-se semelhantes quanto ao conhecimento sobre livros e autores indígenas, ou seja, os mesmos $63 \%$ das entrevistadas desconhecem a existência deles. A respeito da existência de materiais didáticos nas escolas, $42 \%$ das participantes expressaram desconhecimento, enquanto $58 \%$ descreveram sua natureza contida em textos, livros infantis e didáticos, pesquisas na internet, materiais produzidos em cursos de formação e livros ligados às legislações indigenistas. A percepção trazida sobre o conteúdo desses materiais é de substância crítica, isto é, $80 \%$ das professoras consideram superficiais e empobrecidos de detalhes. Dos $20 \%$ restantes, 10\% assumiram que os materiais são bons, porém necessitam ser reavaliados. Dentre aquelas que produzem seu próprio material e também orientam sua prática pedagógica através de legislações próprias, e sob a base de pensadores indígenas, também consideraram os materiais restritos. Embora sejam colocados pensadores indígenas como fundamento de suas práticas, esses não foram citados quando indagadas. 
QUADRO 1 - Palavras associadas ao indutor índio

\begin{tabular}{|l|l|l|l|l|l|}
\hline 1.Antiguidade & 10.Cultura & 19.Discriminação & 28.Liberdade & 37.Persistência & 46.Selvagens \\
2.Apropriação & 11.Dança & 20.Festividades & 29.Luta & 38.Pescar & 47.Sobrevivência \\
3.Beleza & 12.Descoberta & 21.Formação & 30.Mandioca & 39.Preconceito & 48. Superação \\
4.Brasil & 13.Desigualdade & 22.Guerreiro & 31.Nadar & 40.Preservação & 49. Terra \\
5.Canoa & 14.Desvalorizados & 23.Heróis & 32.Natureza & 41.Raça & 50.Tradição \\
6.Cidadãos & 15.Determinação & 24.História & 33.Nudismo & 42.Rede & 51.Tribo \\
7.Comida & 16.Diferenças & 25.Igualdade & 34.Oca & 43.Respeito & 52.União \\
8.Coragem & 17.Dignidade & 26.Invasão & 35.Origem & 44.Ritual & 53.Vencedor \\
9.Cotas & 18.Direito & 27.Justiça & 36.Paz & 45.Sabedoria & 54.Vida \\
& & & & & \\
\hline
\end{tabular}

Fonte: Resultados da pesquisa

Enquanto uma organização de imagens e linguagem simbolizando situações e ações, a identificação da representação social permite a evocação dos sentidos manifestos nas relações interpessoais mediados na reprise que os sujeitos fazem sobre a realidade através das palavras. Desse modo, as professoras atribuíram forma nas derivações à palavra índio, inferindo valores e conceitos numa provável elaboração do conhecimento advindo de suas experiências profissionais e pessoais.

A dimensão das palavras associativas incidiu na abrangência de elementos representacionais como valores, sentimentos, simbolismos e posicionamentos remetidos ao que se percebe na cultura indígena significando "escolher um dos paradigmas estocados na memória e estabelecer uma relação positiva ou negativa com ele" (MOSCOVICI, 2015, p.63). Após a associação foi elaborada a divisão das categorias de análise que compõem cada domínio semântico interligadas entre si.

QUADRO 2 - Categorias de análise

\begin{tabular}{|l|c|}
\hline \multicolumn{1}{|c|}{ CATEGORIAS } & $\%$ \\
\hline Identidade (Guerreiro, Vencedor, Selvagens, Cidadãos, Heróis) & 10 \\
\hline $\begin{array}{l}\text { Costumes (Mandioca, Oca, Nudismo, Canoa, Dança, Tribo, Rede, Raça, Ritual, Pescar, Nadar, Natureza, } \\
\text { Comida, Cultura, Tradição, Preservação, Festividade) }\end{array}$ & 31 \\
\hline Passado (Descoberta, Invasão, História, Antiguidade, Brasil, Formação, Origem) & 13 \\
\hline $\begin{array}{l}\text { Exclusão/Valores (Terra, Apropriação, Luta, Sobrevivência, Cotas, Discriminação, Diferenças, } \\
\text { Desvalorizados, Superação, Desigualdade, Preconceito, Determinação, Coragem, Dignidade, Direito, } \\
\text { Igualdade, Liberdade, Justiça, Persistência, Respeito, União, Sabedoria) }\end{array}$ & 41 \\
\hline Não categorizável (Vida, Paz, Beleza) & 5 \\
\hline \multicolumn{1}{|c|}{ Total } & 100 \\
\hline
\end{tabular}

Fonte: Resultados da pesquisa

Na primeira categoria, a representação do índio pode estar referida à imagem idealizada e icnográfica ainda vista pela "literatura romântica produzida no século XIX, como nos livros de José de Alencar, em que são apresentados índios belos e ingênuos, ou valentes guerreiros e ameaçadores 
canibais, ou seja, bárbaros, bons selvagens ou heróis" (SILVA, 2011, p. 133). A última palavra associada remete a valorização e compreensão dos índios enquanto sujeitos de direitos, podendo estar atrelada tanto no direito de perpetuação de suas tradições, valores e costumes, quanto do acesso aos bens que norteiam o mundo como um todo. A imagem de um índio selvagem e arcaico perpetuado na literatura entra em contraste com a imagem de um índio atual, despossuído de atributos estanques. A matéria prima de compreensão da identidade indígena fornecida pela história, pela memória coletiva e por fantasias pessoais é processada e passa por rearranjos de significação que podem ou não manter tendências ao longo do tempo e do espaço. Fixaridentidades do passado na contemporaneidade pode tanto funcionar como instrumento de estigmatização, fortalecendo a eficácia do simbólico como também de resistência cultural pelos grupos estigmatizados.

Na segunda categoria, “Costumes", várias são as palavras denotando a interpretação do índio marcado por práticas cotidianas e de sobrevivência, e por elementos culturais estereotipados historicamente. Emerge a representação de um índio genérico, de identidade homogeneizada, vivendo em comunhão com a natureza, nu na mata, morando em ocas. A cultura indígena é então desarticulada pelo paradigma desincorporado dos elementos da cultura dominante. Algumas palavras, como "Cultura", "Costumes", "Crença”, "Tradição" e "Preservação", expressam um aparente desejo em se manter certos aspectos de definição, resistência e manutenção das manifestações culturais pela continuidade e conservação consoantes aos seus próprios padrões culturais.

$\mathrm{Na}$ categoria seguinte aparece a representação de um índio pertencente à formação e descobrimento do Brasil. A dicotomia das palavras "Invasão" e "Descobrimento", pode estar relacionada de um lado à aceitação dos discursos colonizadores pautados na noção humanizada e catequizadora do descobrimento do Brasil, de um índio passivo, rendido por costumes e crenças impostas; e, de outro lado, um índio ativo, questionador de uma epistemologia de seu povo, resistente a aceitar o modo pelo qual sua história foi contada e aprisionada em significações alheias. Desse modo, os significados são reistoricizados pela contestação das forças heteronômicas de reificação. A operacionalidade das representações sociais também se manifesta sobre as resistências às inovações simbólicas de ameaça a sua produção cultural de formação identitária.

A classe de palavras categorizadas com maior frequência "Exclusão/Valores" pressupõe a percepção do índio enquanto sujeito excluído socialmente e ao estabelecimento da busca por seus direitos e por sua cidadania. Esses valores, que também podem ser traduzidos como sentimentos de ordem política, trazem consigo as implicações afetivas interligadas às representações sociais na elaboração psíquica da realidade social assimilada pela consideração de como está sendo entendida 
a situação do índio, necessitando de "Coragem", "Superação", "Determinação", "União" e "Persistência", para alcançar o "Direito", a "Igualdade", a "Liberdade", a "Justiça" e o "Respeito".

Por ancoragens do novo no velho e da objetivação identificada pelas palavras como referentes daquilo que se pensa e sente sobre índio pela exteriorização interpretativa das palavras evocadas, foram tornando o conhecido a partir do que já é conhecido, ao mesmo tempo em que foram desestabilizadas referências num processo dinâmico (MOSCOVICI, 2015, p. 216).

QUADRO 3 - O que define um índio?

\begin{tabular}{|l|}
\hline 1. Uma comunidade indígena que tem parentescos ou vizinhança entre si. \\
\hline 2. Povo extremamente religioso com uma cultura que eles valorizam e um censo de comunidade inigualável \\
\hline 3. Uma pessoa que vive conforme suas tradições que luta pela preservação de sua raça e de seus valores. \\
\hline 4. Um ser humano com cultura diferente da nossa. \\
\hline 5. Seu modo de vida e sua cultura. \\
\hline 6. Uma pessoa igual ao negro e ao branco. \\
\hline 7. O índio primitivo que os portugueses encontraram aqui, os índios verdadeiros. \\
\hline 8. Hoje a mistura é muito grande e eles perderam sua essência. \\
\hline 9. Sua cultura e crença. \\
\hline 10. Ser igual a qualquer um de nós com direitos e deveres perante Deus e o homem. \\
\hline 11. Pessoas que muito contribuíram para nossa cultura. \\
\hline 12. Suas origens. \\
\hline 13. Pessoas livres, porém grandes conservadores de sua cultura. \\
\hline 14. Um povo que se perdeu ao longo da história e do progresso. \\
\hline 15. Um povo com cultura particular e suas raízes brasileiras. \\
\hline 16. Povo guerreiro que luta por seus direitos. \\
\hline 17. Sua identidade mantendo seus costumes e tradições valorizados. \\
\hline 18. Seu modo de viver, seus costumes e suas tradições formando sua identidade e definindo a qual povo \\
Pertence. \\
\hline 19. Sua cultura, modos de viver e tradições e identidade de seu povo. \\
\hline
\end{tabular}

Fonte: Resultados da pesquisa

No estabelecimento consensual de um universo de interpretação, baseadas em suas experiências e nas teorias do senso comum, as pessoas respondem e agem sobre seus questionamentos elaborando a construção social do real. As participantes da pesquisa enquanto categorias profissionais estão submetidas à influência de outro universo; é este "Universo Reificado", regulado por explicações científicas a que parecem também recorrer (MOSCOVICI, 1978, p.20). No quadro das teorias desses dois universos, as repostas aos questionamentos contidos na pesquisa são estruturadas. As palavras emergidas na primeira etapa da análise dos dados se assimilaram na formação das frases, constituindo um instrumento importante no alcance dos objetivos da pesquisa.

Pelas respostas das professoras, foi possível evidenciar que cerca de $63 \%$ delas acreditam que "o índio é definido pela sua cultura", na consideração sobre sua contribuição na formação da 
identidade brasileira. Enquanto desdobramento dessa referência à manifestação cultural surgem a dimensão da religiosidade, da ancestralidade, da valorização comunitária, das tradições e manutenção de legados. O índio, nessa direção, é definido por aquilo que ele fez dele mesmo. A palavra "raça" aparece configurada num sentido de pertencimento e compartilhamento cultural exclusivo.

Aproximadamente $15 \%$ atribuem sentido à busca pela afirmação de direitos e deveres, o “índio visto como um cidadão", pelo direito de perpetuação do seu modo de viver com garantias à acessibilidade a outras culturas, mas acompanhado do adjetivo referente à sua contínua requisição. Essa contrapartida revela o modo de percepção do índio na sociedade, ao mesmo tempo em que se descortina o modo pelo qual se estabelece a relação com os não índios, ou seja, por meio da busca, da luta e da persistência.

Verificou-se também que $15 \%$ das entrevistadas conferem ao índio uma espécie de "impureza cultural" originada da convergência com outras culturas ao longo da história. As concepções idealizadas sob comparações entre o "verdadeiro" e o "falso" índio, trazem à tona representações baseadas em características circunscritas num modelo identitário, sob o qual a mutabilidade e as concessões culturais não se fazem permitidas. "Ser índio" é traduzido pela conservação e "pureza cultural", pelo simbolismo estanque de impedimento às novas aquisições culturais, e sua justificação institui-se pela ideia de perda de originalidade advinda do processo de aculturação.

O sistema de referência das docentes, reinterpretado socialmente por suas experiências individuais, parece ser resultante da força de hegemonia histórica de fixação de limites à interculturalidade indígena. Tudo aquilo que poderia suscitar como novo, por sua força anacrônica sintetiza-se à representação já apartada. A memória, enquanto elo do passado com o presente, reconstrói a história, entretanto por uma representação incompleta desse passado, o que é rememorado é interpretado conforme os desejos, interesses e necessidades de cada grupo ou sociedade no presente.

Os outros 7\% restantes concebem certa humanidade ao índio, como um "igual", "uma pessoa", "um ser humano", congregando a indignidade, a brasilidade e a humanidade. Diferentemente de outras associações o contexto de desconhecimento e estranhamento da diferença é colocado num segundo plano. As representações sociais definem simultaneamente tanto o caráter, no caso do estímulo "índio", como a resposta que ele incita, assim como em uma situação particular, elas determinam o que é o quê e quem é quem (MOSCOVICI, 2015, p.100). 
QUADRO 4 - O que você acha que as pessoas pensam sobre os índios?

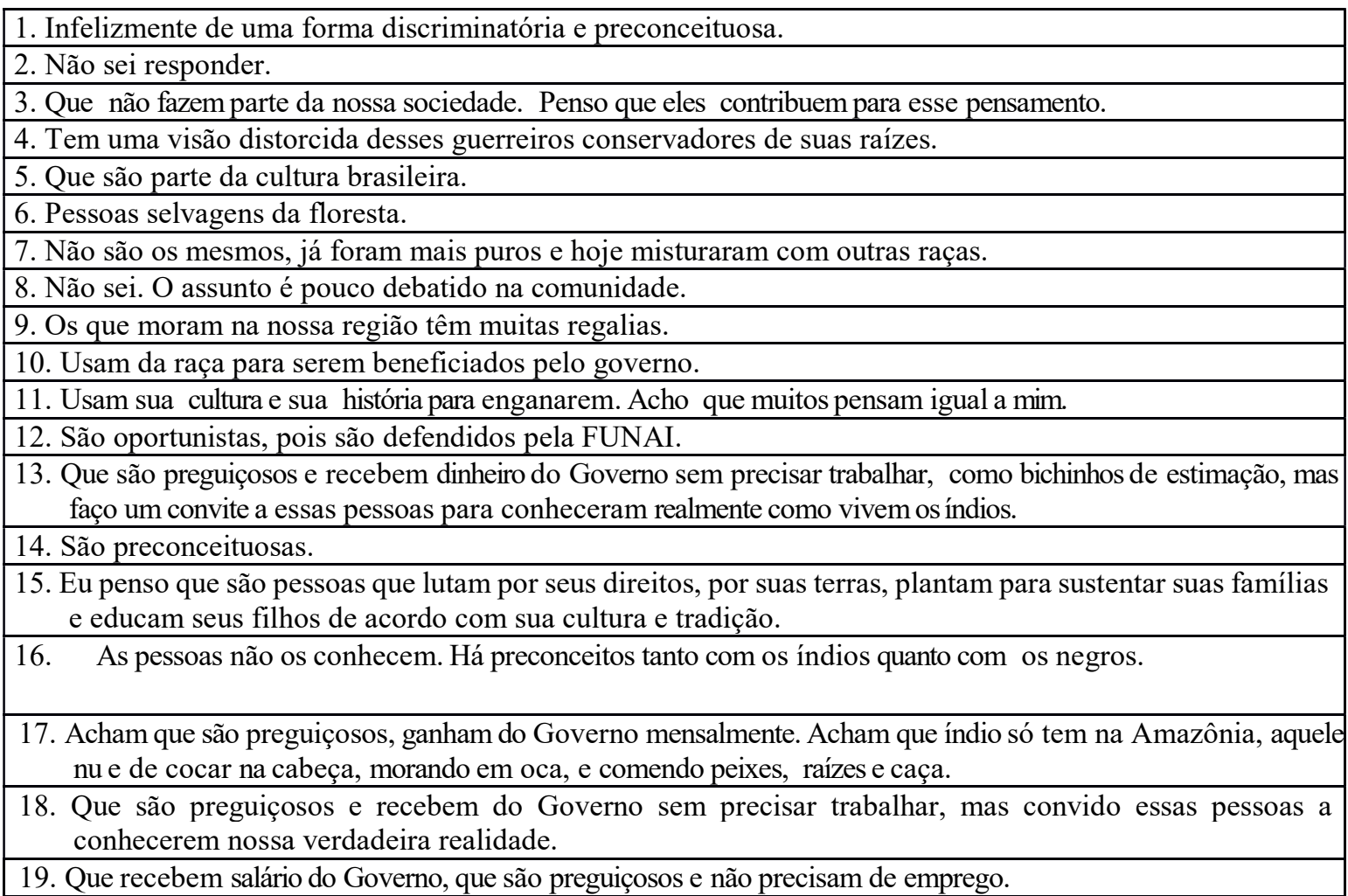

Fonte: Resultados da pesquisa

Embora a questão fosse sobre o que as outras pessoas pensam sobre os índios, $21 \%$ das participantes responderam em primeira pessoa. A intenção, na elaboração da pergunta, foi a da tentativa de promoção de respostas mais livres com possibilidades de revelar outras manifestações representativas.

Como mais evidente, em $42 \%$ das respostas, o índio aparece como sendo beneficiado por políticas públicas de agências específicas, aparecendo também o substantivo "raça", utilizado como instrumento de busca e favorecimento das vantagens, e o substantivo "cultura" e "história" como mecanismo de fraude não especificada. A palavra "raça", diferente do resultado disposto no quadro 3, adquire primeiro uma significação ideológica de pureza racial apresentada enquanto um saber representativo e normativo de explicação racional da diferença. Já na sua segunda evocação, é interpretada como um instrumento sócio-político que opera sob aspectos econômicos. Enquanto uma construção linguística, discursiva e social, sua mutabilidade semântica funciona para manter ou desestabilizar determinadas ideias.

A representação social do "índio beneficiário e aproveitador" sustenta-se pela ancoragem do conceito tracejado de características estereotipadas, contrário aos ditames e conveniências modernas que, por ideias objetivadas, constituem um discurso justificador também pela 
fundamentação das relações de paternalismo com a sociedade nacional e pelas instituições tutelares deliberativas das políticas indigenistas.

Ainda que com menos expressividade, revela-se novamente "o índio selvagem" e o "índio impuro", de identidade imprecisa e não permissivo a concessões culturais. Numa perspectiva dialética de representação, ao mesmo tempo em que o índio necessita se transfigurar num modelo moderno de pessoa, ele também deve manter sua cultura e sua "selvageria" como possível símbolo de sua identidade. Assim como a cultura, a identidade é cambiante, e sua falta estaria na "raiz da angústia psíquica do homem moderno, sintoma da necessidade de nos vermos em termos de nós e eles; de opor nós a eles, e por conseguinte, da nossa impotência de ligar um ao outro" (MOSCOVICI, 2003, p. 50). A “discriminação", "preconceito" e "visão distorcida”, dito em $15 \%$ das respostas talvez represente uma noção dessa impotência.

Como grande parte das respostas afluíram para um sentido sócio-político e econômico, as representações ligam-se à sustentação histórica de processos comunicativos permanentes, e nesse caso os adjetivos e denominações dirigidos a determinados grupos servem como instrumento justificador e explicativo dos impedimentos ao progresso e ao desenvolvimento econômico do país, quando esses mesmos grupos não se submetem à lógica dominante. Em contrapartida, aparece novamente, ainda que com menos eloquência, o "índio que luta por seus direitos", denotando um deslocamento da diferença tratada como atentatória ao desenvolvimento.

Quatro das dezenove participantes são professoras indígenas, e uniformizando suas respostas, lançaram o desafio aos não índios sobre a apuração da verdadeira realidade dos povos indígenas, questionando seu reconhecimento e sinalizando a invisibilidade social. A distinção de respostas das professoras da escola indígena e parte das professoras das escolas não indígenas, na identificação das representações sociais formadas, aparece como um campo de disputa pela representação. Nas primeiras, pela contestação e desestabilização de certas representações, e parte das últimas, pela permanência dos regimes de representação.

Pela aparente prática regular de ideias objetivadas, a abstração posta na associação livre de palavras ganha nas frases uma maior tangibilidade e materialização, ancorando valores, desejos, ideias e imagens sobre o índio em manifestações vivenciadas por influências de universos consensuais e reificados, sob aspectos científicos, sociais, políticos e culturais, "da representação na realidade da representação, transformando a palavra que substitui a coisa, na coisa que substitui a palavra" (MOSCOVICI, 2015, p. 71). 


\section{CONSIDERAÇÕES FINAIS}

A pesquisa como um todo possibilitou verificar as representações sociais das participantes sobre o índio, descortinando as ilações de sua produção, de perspectivas sociais, históricas, políticas e culturais aos acontecimentos pelos quais surgem sistemas de referências construídos na dialética de reedição dessas mesmas produções.

O papel das representações sociais na formação de sistemas e esquemas de referência promove a facilitação da comunicação, orientam condutas e contribuem para forjar a identidade grupal e o sentimento de pertença do sujeito a um determinado grupo. A medida a ser refletida e problematizada seria a de como se promove a afirmação dessa identidade, utilizando critérios de condição e de conceituação do que é o outro.

O conceito de índio determina conteúdos, metodologias e formas de transmissão e socialização do conhecimento que serão utilizadas nas atividades escolares. Ele é a expressão de uma determinada consciência social cindida aos processos comunicativos integrados nas esferas institucionais; e na comunidade escolar, suas representações podem ser debatidas, pois conhecê-las e reconhecê-las nas próprias manifestações cotidianas pode auxiliar na sua ressignificação e no posterior reflexo nas práticas.

A ação educativa enquanto ação cultural e política, de trocas de experiências mútuas, num espaço ecológico de cruzamento de culturas, gera o conflito entre o conhecimento como regulação e o conhecimento como emancipação no qual está localizado o imprescindível papel do professor, de orientação e formação de subjetividades inseridas nas representações de raça, etnia ou classe social. Assim, ela não pode exonerar-se da reflexão e análise das condições sociais, históricas e culturais sobre o homem, pois a educação não está isolada das condições humanas da sociedade em que se insere.

Atrelada ao panorama da diversidade cultural, a temática indígena está alçada, sobretudo, no respeito ao outro e à alteridade, considerando a diferença para pensá-la não como um coeficiente externo, mas de lançar um olhar provocador, reflexivo e transformador na compreensão e condução da diferença. Pressupondo a alteridade enquanto diversidade de identidades, da interação como o não-idêntico, da constituição relacional de contrastes culturais, parece indispensável à realização de pesquisas empíricas que visem ao tratamento do tema, principalmente no local primordial de socialização dos sujeitos e do conhecimento. A ampliação de novos saberes pode aprofundar os poderes sociais tornando os sujeitos conscientes, possibilitando alguma 
transformação. Tal processo possibilita a contestação, desestabilização e implosão de identidades hegemônicas constituídas por regimes estanques de representação.

Embora haja esforços impingidos na reconfiguração da educação na contemporaneidade, em específico no Brasil, através de regulações normativas e legislativas, ainda existem obstáculos significativos de impedimento de suas materializações. As questões de natureza legal são direcionamentos pelos quais se deseja a evidência das práticas; entretanto, as ações dos profissionais de educação são permeadas por questões de ordem subjetiva e objetiva pelas quais as representações sociais podem assumir uma força propulsora de nível mais elevado. Enquanto sistemas emancipados de significações sociais, resultam dos compromissos contraditórios sob a dupla pressão de fatores ideológicos e de refreamentos relativos ao funcionamento efetivo das leis educacionais.

As legislações direcionadas à inclusão da pluralidade cultural nas escolas implicam considerar as representações sobre os grupos minoritários analisando os significados políticopedagógicos da formação docente e dos projetos de sociedade em que as escolas se baseiam. Em se tratando de formação docente, a redefinição de concepções permite novas maneiras em conceber a diversidade advinda de diferentes grupos sociais, sendo promovidas através de suas próprias narrativas, de suas realidades e de sua história cultural; a exigência de um processo de repolitização que garanta sua autoria nos projetos formativos.

\section{REFERÊNCIAS}

BARDIN, Laurence. Análise de conteúdo. São Paulo: Edições 70, 1979.

BRASIL, IBGE. Censo demográfico, 2010. Disponível em: <www.ibge.gov.br > . Acesso em: 4 abr. 2016.

BRASIL, Ministério da Educação. Secretaria da Educação. Base Nacional Comum Curricular. Brasília, 2015, p.24-84.

BRASIL, Ministério da Educação. Secretaria da Educação Básica. Indagações sobre o currículo: currículo, conhecimento e cultura. Brasília: MEC/SEB, 2008.

BRASIL. Lei 11.645/08 de 10 de março de 2008. Diário Oficial da União, Poder Executivo, Brasília.

BRASIL. Ministério da Educação. Parâmetros Curriculares Nacionais: pluralidade cultural. Brasília: Secretaria de Educação Fundamental, 1997. 
BRASIL, Ministério da Educação; Secretaria de Educação Básica. Referencial Curricular Nacional para as Escolas Indígenas. Brasília: MEC/SEF, 1998.

BRASIL/CNE. Resolução CNE/CP n. 1, de 15 de maio de 2006.

CORAZZA, Sandra Mara. Currículo na contemporaneidade: formação Continuada: Blumenau, 2008.

FREIRE, José Ribamar Bessa. Cinco ideias equivocadas sobre o índio. Revista do Centro de Estudos do Comportamento Humano (CENESCH). Manaus, n. 01, p.1-33. set. 2000.

JANOARIO, Ricardo de Souza. Gestão multicultural em educação. 2008. Dissertação (Mestrado em Educação) - Programa de Pós- Graduação em Educação, Universidade Federal do Rio de Janeiro, Rio de Janeiro, 2008, p. 55-61.

MACEDO, Elizabeth. Currículo e conhecimento: Aproximações entre educação e ensino. Cadernos de Pesquisa, Rio de Janeiro, v.42, n.147, p.716-737, set./dez. 2012.

MINAYO, Maria Cecília de Souza. Pesquisa social: teoria, método e criatividade. 8. ed. Petrópolis/RJ: Vozes, 1998.

MOSCOVICI, Serge. Representações sociais: investigações em psicologia social. 2. ed. Petrópolis/RJ: Vozes, 2011.

MOSCOVICI, Serg. A representação social da psicanálise. Trad.: Álvaro Cabral. Rio de Janeiro: Zahar Editores, 1978.

OLIVEIRA, D. C.; MARQUES, S. C.; GOMES, A. M. T.; TEIXEIRA, M. C. T. Análise das evocações livres: uma técnica de análise estrutural das representações sociais. In: MOREIRA, S. P.; CAMARGO, B. V.; JESUÍNO, J. C.; NÓBREGA, S. M. (Org.). Perspectivas teóricometodológicas em representações sociais. Paraíba: UFPB, 2005, p. 573-603.

RICHARDSON, Roberto Jerry. Pesquisa social: métodos e técnicas. 3. ed. São Paulo: Atlas, 1999. Cap.12, p.184-205.

SEMPRINI, Andrea. Multiculturalismo. Bauru, SP: EDUSC, 1999.

SILVA, Edson. Povos indígenas e o ensino: reconhecendo o direito à inclusão das sociodiversidades no currículo escolar com a Lei n. 11.645/2008. Revista Polyphonía, v. 22/1, jan./jun. 2011, p.122-138.

SILVA, Marcos; FONSECA, Selva Guimarães. Ensinar história no século XXI: Em busca do tempo entendido. Campinas, SP: Papirus, 2007, p.36-48.

SILVA, Tomaz Tadeu da. Currículo e identidade social: territórios contestados. In: SILVA, Tomaz Tadeu da (Org.). Alienígenas na sala de aula. Petrópolis/RJ: Vozes, 1995, p. 190- 207. 